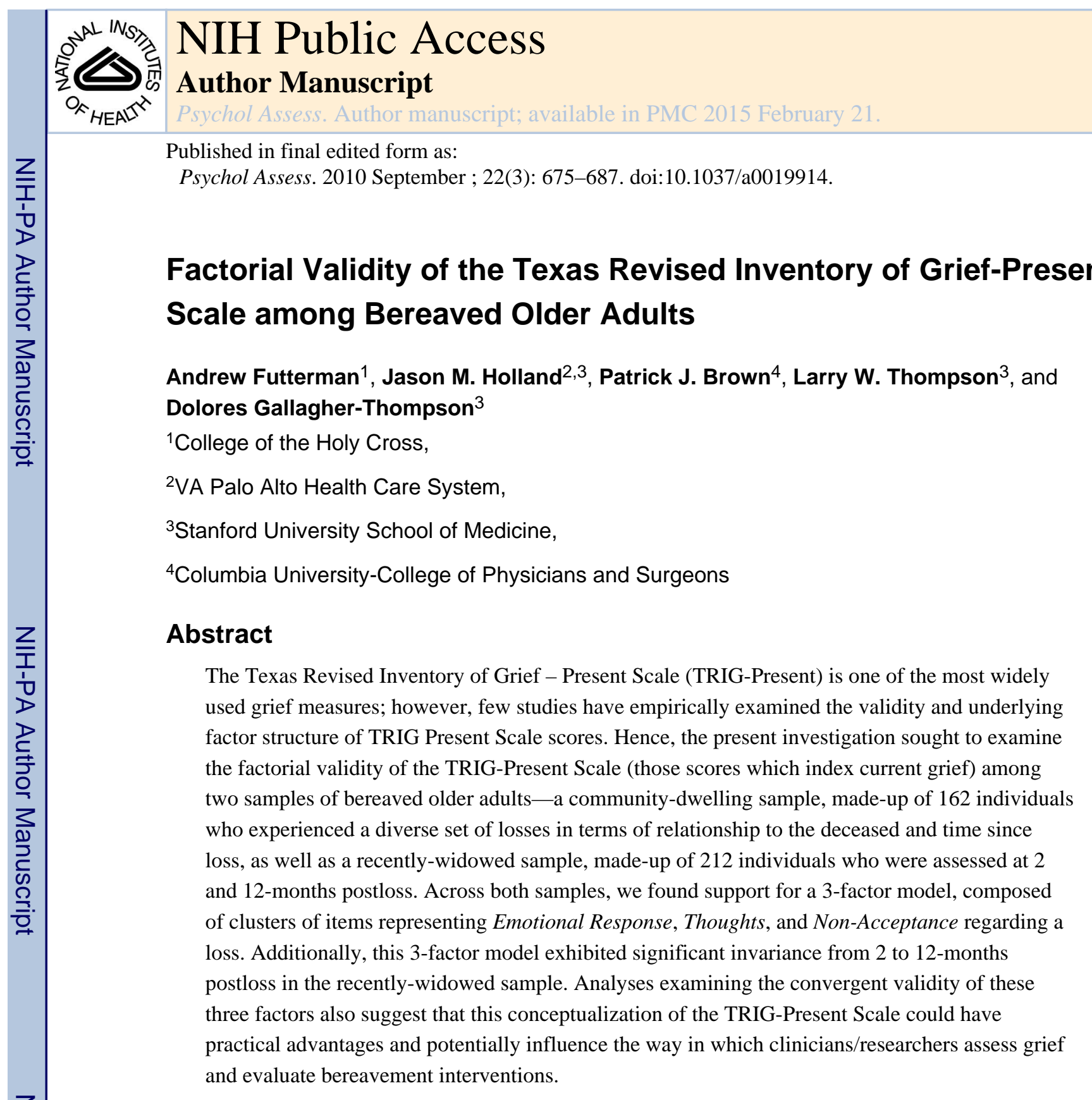

\title{
Keywords
}

Grief; Bereavement; Measurement; Factor Analysis; Older Adults

\footnotetext{
For correspondence regarding this paper, contact Andrew Futterman, Department of Psychology, College of the Holy Cross, Worcester, MA. 01610..

Andrew Futterman, Department of Psychology, College of the Holy Cross; Jason M. Holland, Center for Health Care Evaluation, Palo Alto Veteran's Affairs Medical Center and Stanford University School of Medicine; Patrick J. Brown, Division of Geriatric Psychiatry, Columbia University-College of Physicians and Surgeons; Larry W. Thompson and Dolores Gallagher-Thompson, Department of Psychiatry and Behavioral Sciences, Stanford University School of Medicine.

Publisher's Disclaimer: The following manuscript is the final accepted manuscript. It has not been subjected to the final copyediting, fact-checking, and proofreading required for formal publication. It is not the definitive, publisher-authenticated version. The American Psychological Association and its Council of Editors disclaim any responsibility or liabilities for errors or omissions of this manuscript version, any version derived from this manuscript by NIH, or other third parties. The published version is available at www.apa.org/ pubs/journals/PAS.
} 
The majority of early bereavement studies before the late 1970's focused primarily on global indices of mental health, such as depression, and aspects of general daily functioning, such as coping and social support (Stroebe \& Stroebe, 1987). To fill the need for a direct measure of grief intensity, Faschingbauer, DeVaul, and Zisook (1977) developed the Texas Inventory of Grief that assessed an array of past and present loss-related thoughts, emotions, and behaviors. This measure was expanded into the Texas Revised Inventory of Grief (TRIG), which was composed of 13 items measuring "present grief" (TRIG-Present) and 8 items assessing "past disruption due to loss" (TRIG-Past; Faschingbauer, 1981; Zisook, DeVaul, $\&$ Click, 1982). The TRIG has been used in numerous studies and represents one of the most widely used and well known grief measures (Neimeyer, Hogan, \& Laurie, 2008). Few studies, however, have rigorously examined the reliability and validity of TRIG-Past or TRIG-Present scores.

Given that most researchers and clinicians are typically interested in assessing current grief as well as the methodological and conceptual challenges associated with retrospective accounts of emotional well-being, we focused solely on the TRIG-Present in the present study. We aimed to examine the factorial validity of TRIG-Present scores in two samples of bereaved older adults. The first sample consisted of community-dwelling older adults who have experienced a diverse set of losses in terms of relationship to the deceased and time since loss. The second sample consisted of recently bereaved widows and widowers at 2 and 12-months after their loss.

We had four specific goals in this study: (1) Identify the underlying factorial structure of TRIG-Present scores. (2) Determine whether this factor structure is invariant across the community-dwelling and recently-widowed samples. (3) Establish whether TRIG-Present scores are longitudinally invariant in the recently-widowed sample from 2 to 12 -months following a loss. (4) Finally, examine the convergent validity of TRIG-Present factor scores using salient demographic and loss context variables (e.g., age, sex, relationship closeness, unexpectedness of loss), measures of depressive symptoms and physical health, religiosity variables (e.g., organizational/non-organizational religious involvement, subjective religiosity), and personality variables (e.g., extraversion, openness to experience, neuroticism). What follows elucidates the TRIG's background and significance, past psychometric studies of the TRIG, and how the current investigation contributes to this literature.

\section{Background and Significance of the TRIG}

The TRIG was initially regarded as a measure of "unresolved grief" (Faschingbauer, 1981), but more recently it has been conceptualized as a measure of normal grieving (Neimeyer et al., 2008). Several studies have compared the TRIG-Present to the Inventory of Complicated Grief (ICG), a more recent measure that attempts to gauge pathological or complicated grief (CG) symptoms, such as severe separation distress, a sense of meaninglessness in life, and functional impairments resulting from loss (Prigerson et al., 1995). In particular, two recent confirmatory factor analytic studies found good fit for a model in which items from the TRIG-Present Scale and items from the ICG loaded on separate, but correlated, latent factors (Boelen \& van den Bout, 2008; Dillen, Fontaine, \& Verhofstadt-Denéve, 2008). Other 
investigations have also found the ICG to be better than the TRIG-Present at predicting detrimental outcomes, such as quality of life impairments, concurrent psychopathology, and general health (Boelen \& van den Bout, 2008; Boelen, van den Bout, de Keijser, \& Hoijtink, 2003; Prigerson et al., 1995). Taken together, these studies suggest that the TRIG-Present and ICG might tap into two different (yet related) constructs, and the TRIG-Present likely measures more normal grief experiences (e.g., missing the deceased, crying when thinking about the deceased).

Although much attention has been paid to CG in recent years, the study of normal grief phenomena deserves attention in its own right and has potential for increasing our understanding of bereavement as a common life event that often serves as a developmental challenge in later-life. Notably, by the age of 65 , about $50 \%$ of all women and $10 \%$ of all men experience the loss of a spouse, and these figures then rise to $80 \%$ and $40 \%$, respectively, by age 85 (Rosenzweig, Prigerson, Miller, \& Reynolds, 1997). Of course, the cumulative loss experienced by older adults surpasses these figures, as the loss of siblings and friends exceeds spousal loss by a factor of three-to-one and nine-to-one, respectively (Hays, Gold, \& Peiper, 1997).

Despite the frequency of such losses, the best evidence from a longitudinal, prospective investigation of older bereaved spouses suggests that only about $16 \%$ of widows and widowers show enduring symptomatology as a result of loss (Bonanno et al., 2002). In contrast, the vast majority of individuals seem to be resilient, and about $45 \%$ of the participants from this same longitudinal study exhibited minimal depressive and grief symptoms six months afterward. Other studies have noted that many bereaved individuals not only show a lack of symptoms but also report positive aspects of their grief experience, such as becoming closer with family, taking on new roles, or gaining greater insight (Davis, 2008). These experiences deserve study in their own right and better understanding of more normative reactions to loss could help clarify how older adults transform, overcome, and cope with bereavement-related adversity.

Greater understanding of the construct of normal grief, as opposed to CG, could also have an impact on assessment and intervention. For instance, in one study of bereaved Alzheimer's caregivers, the TRIG-Present and ICG scores demonstrated differential changes in response to two types of intervention: cognitive and behaviorally oriented strategies influenced CG symptoms, whereas information and emotional support influenced normal grief symptoms (Holland, Currier, \& Gallagher-Thompson, 2009). Given that different types of bereavement interventions may differentially influence specific kinds of grief symptoms, refinements in the measurement of normal grief and other bereavement-related phenomena would likely improve outcome evaluation-an issue of supreme importance considering the small effects observed in bereavement intervention research overall (Currier, Neimeyer, \& Berman, 2008). Moreover, if normal grief were shown to be multifaceted, it may be that bereavement interventions impact some aspects of grieving but not others, and intervention effects could be diluted when grief is only examined as a unitary construct. 


\section{Past Psychometric Studies of the TRIG}

Despite the potential importance of improving the measurement of normal grief, limited information is available on the psychometric properties of TRIG scale scores. In the initial validation studies of the TRIG, 58 candidate items were given to a sample of more than 200 bereaved individuals who were predominantly young women, temporally distant from the loss event, and grieving the loss of a variety of relationships (Faschingbauer, 1981; Zisook et al., 1982). Factor analyses of this expanded questionnaire identified two distinct factors that now make up the TRIG-Present and TRIG-Past scales (Faschingbauer, 1981). Scores on the 13 TRIG-Present items demonstrated reasonable internal consistency $(\alpha=.86)$ and splithalf reliability $(r=.88)$. Background characteristics and loss-context variables were also found to be related to TRIG-Present scores in expected directions. For example, women reported higher levels of grief than men, and individuals who reported losing an emotionally-close relationship had higher levels of grief than those who lost a more distant relationship (Faschingbauer, 1981).

Two more recent factor analytic studies have obtained results that diverge somewhat from Faschingbauer's (1981) initial findings. Both of these studies were cross-sectional and only conducted exploratory analyses using a single sample. One study examined the French version of the TRIG among a sample of 154 young adults and found evidence in support of three distinct factors that tapped into Present Feelings, Past Behavior, and Related Facts (Paulhan \& Bourgeois, 1995). Notably, this investigation used five supplementary items that inquired about other information related to the loss (e.g., funeral attendance, anniversary effects), and the obtained factors included combinations of items from the original TRIGPresent and TRIG-Past scales as well as from these additional five items. Another investigation that examined the factor structure of a Spanish version of the TRIG among 134 Latino older adults also found support for a three-factor solution that gauged Present Feelings, Past Behaviors, and Disbelief (Wilson, 2006). These factors included combinations of items drawn from both the TRIG-Present and TRIG-Past scales and thus relating to both present and past grief experiences, making a total score derived from these factor-derived subscales conceptually difficult to interpret.

\section{Contribution of the Present Study}

Rather than being seen as a unitary construct, present feelings of normal grief are often conceptualized as being composed of several core phenomena. In particular, Burnett, Middleton, Raphael, and Martinek (1997) have suggested that normal grief is made up of three broad experiences, including images and thoughts (e.g., preoccupation with thoughts about the deceased), grief (e.g., emotional responses like sadness/crying), and acute separation distress (e.g., looking for the deceased in familiar places). Additionally, stage theorists have conceptualized normal grief as occurring in distinct and predictable phases over time (Jacobs, 1993; Kübler-Ross \& Kessler, 2005). For example, Jacobs (1993) theorized that normal grief is initially characterized by a sense of disbelief and, following periods of yearning, anger, and depression, finally concludes with acceptance of the loss. Two recent empirical tests suggest that various indicators of grief (e.g., anger, yearning, sadness) may predictably wax and wane at different periods of time (Holland \& Neimeyer, 
in press; Maciejewski, Zhang, Block, \& Prigerson, 2007)—a process that would presumably impact the intercorrelations among grief indicators at any one point in time. From a measurement perspective, such a process of change would suggest that demonstrating longitudinal invariance of a grief measure would be difficult. No study to date, however, has examined the factorial stability of TRIG-Present scores across time.

The TRIG-Present includes items that inquire about a range of grief-related phenomena, making it a good measure to test conceptual models that view grief as being made up of multiple components. In keeping with stage theories of grief, small clusters of items could emerge, perhaps gauging (1) non-acceptance of a loss, (2) yearning/missing the deceased, (3) feelings of being upset/angry, and (4) crying/sadness. Conversely, we might expect items of the TRIG-Present scores to cluster together as broad factors, such as (1) grief-related thoughts and (2) grief-related emotions-which would be more consistent with Burnett and colleagues' (1997) model. Of course, a three-factor solution is also possible that includes some combination of these item groupings. We will examine which factorial structure best describes the TRIG-Present items and then evaluate the invariance of this structure across the two samples of bereaved older adults, the community-dwelling sample who have experienced a diverse set of losses in terms of relationship to the deceased and time since loss, and the recently-widowed sample.

Finally, this study will examine the convergent validity of TRIG-Present factors. Extant grief studies demonstrate consistent relationships between grief response and several psychosocial variables relating to loss. Among these, intimate relationships to the deceased and those who have experienced a more sudden loss generally tend to report higher levels of grief (Donnelly, Field, \& Horowitz, 2000; Faschingbauer, 1981; Stroebe, Stroebe, \& Schut, 2001). Consistently higher levels of grief are also typically associated with more depressive symptomatology (Strada, 2009), worse physical health (Prigerson et al., 1997), and less religious involvement (Wortmann \& Park, 2008). Several aspects of personality (e.g., higher levels of neuroticism and introversion) have also been associated with more intense grief reactions (Meuser \& Marwit, 2000). By contrast, findings related to age and grief intensity have been more equivocal, with some studies finding that grief responses tend to be less severe with age (Ball, 1977; Kitson, 2000) and others finding more complex associations (e.g., curvilinear associations; Ringdal, Jordhøy, Ringdal, \& Kaasa, 2001; Sanders, 1981).

By undertaking this investigation, we hoped to shed some light on the salient components of grief, how these components change as the time since the loss increases, and to better understand the relationships between these components of grief and those psychosocial variables which research has identified as among the most prominent in the grieving process.

\section{Method}

\section{Participants and Procedure}

Two hundred and twelve recently-widowed older adults ( 99 men, 113 women) and a community-dwelling sample of 162 older adults ( 84 men, 78 women) participated in this study, which took place during the mid-1980's. The age range of all participants was 55-83 
years. The two samples were roughly comparable in age. Means for the recently-widowed and community-dwelling samples were 68.20 years $(S D=7.84$ years) and 70.11 years $(S D=7.65$ years), respectively.

To obtain participants for the recently-widowed group, death certificates at the Los Angeles County Health Department were searched periodically, and all spouses of persons over the age of 55 who had died in the preceding 2-4 weeks were mailed a description of the project and a stamped postcard on which willingness to be interviewed could be indicated. Mailings were sent to 2450 persons. Of the 735 who responded, 212 met the age criterion and also resided within a reasonable distance from the research center to permit home interviews. This response rate is comparable to that obtained in similar bereavement studies (e.g., Lund et al., 1986). Structured interviews and self-report measures of background characteristics, mental and physical health, grief (including the TRIG-Present), religious practices, and personality were completed at 2 and 12-months postloss in the recently-widowed sample. Of the 212 recently-widowed older adults who were assessed at 2-months postloss, 169 (79\%) provided information at 12 -months postloss. At the 2-months postloss assessment, no significant item differences were found on the TRIG-Present between the 169 recentlywidowed older adults who completed both assessments and the 43 participants who dropped out of the study after the 2-months assessment. In general, the recently-widowed sample was primarily Caucasian, relatively well-educated ( $80 \%$ had some high school), of moderate socioeconomic status, and married for many years.

Participants in our community-dwelling sample were recruited from senior centers in Southern California (e.g., the Emeriti Center of USC) and completed the interview and selfreport measures at study entry. This sample of older adults was similar to the community sample used in the initial validation studies of the TRIG-Present in terms of types of loss, time since loss, and socioeconomic status (Faschingbauer, 1981; Zisook et al., 1982). Specifically, these individuals had not lost a spouse in the previous 5-years but reported other significant losses at different times in their lives. Thirty percent reported the loss of a parent, $20 \%$ the loss of a sibling, $4 \%$ the loss of a child, and $46 \%$ the loss of a friend. Twenty-three percent reported that their loss occurred within the previous year, $10 \%$ within the previous 1-2 years, $17 \%$ within the previous 2-5 years, $28 \%$ within the previous 5-10 years, and $23 \%$ over 10 years ago. No significant differences in age, number of years married, family income, or education (self and spouse's) were noted between the community-dwelling and recently-widowed samples. Further details of the sampling procedure and group demographics have been reported in earlier studies (Gallagher, Breckenridge, Thompson, \& Peterson, 1983; Thompson, Gallagher, Futterman, Gilewski, \& Peterson, 1991).

\section{Measures}

To provide evidence of the convergent validity of TRIG-Present scores, we measured several relevant constructs. Specifically, we included measures of (1) background characteristics and loss context variables, (2) mental and physical health, (3) religiosity, and (4) personality characteristics. 
Background Characteristics/Loss Context Variables-Participants' ages were measured in years, and sex was treated as a dummy coded variable ( $1=$ Male, $2=$ Female $)$. Socioeconomic status was measured by a factor score (made up primarily of a participant's occupational and educational status) derived from a previous factor analysis of all background variables used in the study (see Gallagher et al., 1983, for a description). The loss context variables were measured by three items on the original TRIG form. Relationship closeness was measured on a 5-point Likert-type scale from $1=$ Not very close to $5=$ Closer than any relationship I've ever had before or since. Unexpectedness of loss was assessed as either $1=$ Expected or $2=$ Unexpected. Extent of grieving was assessed as a single true-false item: I feel that I have really grieved for my spouse $(1=$ False, $2=$ True $)$.

Mental and Physical Health-Depressive symptoms were assessed using the Beck Depression Inventory (BDI, Beck, Ward, Mendelson, Mock, \& Erbaugh, 1961). The BDI is a multiple-choice symptom scale developed to assess the severity of depression. Twenty-one items measure aspects of depressive features, such as sleep and appetite problems, sadness, guilt, self-reproach, suicidal ideation, and loss of interest in everyday activities. Reliability and concurrent validity for BDI scores with psychiatric diagnoses of depression have been demonstrated in older samples (Gallagher, Breckenridge, Steinmetz, \& Thompson, 1983; Olin, Schneider, Eaton, Zemansky, \& Pollock, 1992). In the current study, reliability for BDI scores was high: Cronbach's alphas were .89 and .88 in recently-widowed and community-dwelling samples, respectively.

Physical health was indexed by a global severity of illness score following the procedure developed by Wyler, Masuda, and Holmes (1968). New or worsened health problems were assigned weights based on Wyler and colleagues' (1968) rankings, which have high concordance with physician judgments (Spearman's rho $=.94$ ). The sum of the severity ratings for each illness provided an index of physical health.

Religiosity-Three aspects of religiosity in later life were assessed in this study: organizational religious involvement, non-organizational involvement, and subjective religiosity. Organizational religiosity included three items assessing formal religious activity, namely frequency of religious service attendance, frequency of meetings with clergy or a religious advisor, and frequency of meetings with religious groups (each measured on 9-point Likert-type scale from $1=$ Never to $9=$ More than once daily). Our measure of Non-organizational religiosity (i.e., informal or private religious experiences) also included three items, which assessed the frequency of praying individually, meditating, and listening to religious programs on TV or radio (measured on the same 9-point Likerttype scale). Subjective religiosity was measured by three related questions about religious importance: importance of religion at the present time, before the death, and just after the death (each measured on a 7-point Likert-type scale from $1=$ Not important at all to $7=$ Extremely important). The content of the religiosity items used in this study and their conceptualization (i.e., as three distinct aspects of religious experience) corresponds with past religiosity research (Ainlay \& Smith, 1984; Chatters, Levin, \& Taylor, 1992). In this study, Cronbach's alphas ranged from .72 to .84 for these three measures. 
Personality-The $16 \mathrm{PF}$ assesses 16 personality factors that are viewed as reflecting primary source or "first-order" traits of personality functioning that when cluster or factor analyzed, yield "second-order" traits, such as extraversion-introversion (i.e., extraversion) and adjustment-anxiety (i.e., neuroticism; Cattell, Eber, \& Tatsuoka, 1970). In an important study, Costa and McCrae (1976) demonstrated that in addition to neuroticism and extroversion (which are measured similarly by the 16PF in younger and older adults, a third cluster emerges that reflects slightly different first-order 16PF traits in younger and older adults. While Costa and McCrae described this third cluster as reflecting "openness to experience," in younger adults it is interpreted as openness to feelings and in older adults it reflects openness to ideas and feelings. Based on correlations reported by Costa and McCrae (1976) between the first-order $16 \mathrm{PF}$ scale scores and the extraversion, neuroticism, and openness to experience clusters for their older adult group (55-82 years), indices for each of these three second-order traits were developed and used in the current study. These indices were averages of the four 16PF first-order trait scores that demonstrated the highest correlations in Costa and McCrae's older sample with extraversion, neuroticism, and openness clusters.

\section{Plan of Analysis}

Exploratory factor analysis-We first examined the underlying factor structure of TRIG-Present scores by fitting several exploratory factor analysis models with the community-dwelling sample. Because initial validation studies of TRIG scale scores utilized only community samples (Faschingbauer et al., 1977; Faschingbauer, 1981), the community-dwelling sample in this study was used as the reference sample for exploratory analyses.

The MPlus program (Version 4, Muthen \& Muthen, 2006) was used for exploratory analyses because it allows for different methods of factor estimation and yields several goodness-offit indices in addition to chi-square. Model fit for the exploratory factor analyses was analyzed using a chi-square goodness-of-fit test as well as the root mean square error of approximation (RMSEA, Browne \& Cudeck, 1993; Steiger, 1990). The chi-square goodness-of-fit test assesses the discrepancy between the observed covariance matrix and the covariance matrix of the fitted model. With large samples, however, virtually any parsimonious model is rejected, and with a small sample model misfit may be undetected. Therefore, we relied primarily on the RMSEA to evaluate the fit of the models. The RMSEA is an index of discrepancy between the model and the data per degree of freedom. An RMSEA value of less than .06 is usually considered indicative of close fit between the model and the data (Browne \& Cudeck, 1992; Hu \& Bentler, 1995). Because the factors were thought to be correlated, the models that extracted more than one factor were rotated with a PROMAX rotation procedure.

Confirmatory Factor Analyses-The best fitting and most substantively meaningful model demonstrated in the exploratory factor analysis of the community-dwelling sample was confirmed in the recently-widowed sample at 2-months following the loss of a spouse and was then confirmed longitudinally in the recently-widowed sample from 2 to 12-months postloss. 
Confirmatory analyses across samples and across times of measurement proceeded according to a hierarchy of progressively more restrictive constraints on the measurement and structural models of two groups as recommended by Horn and McArdle (1992) and Bollen (1989). In this study we tested the invariance hierarchy beginning with factor patterns (equivalence of item-factor associations), followed by factor structure (equivalence of factor loadings), invariance of error variances and error covariances, invariance of factor variances and factor covariances, and finally invariance of factor means. Each level of invariance in the hierarchy typically presumes invariance at lower levels, and when invariance is not demonstrated at one level, subsequent higher level tests of factorial invariance are not performed.

The goal of many factorial invariance studies is to demonstrate the level of invariance present across samples and times of measurement. Achieiving invariance of factor pattern, e.g., constraining the number of factors and the pattern of the free and fixed loadings to be the same across samples, has been described as "formal" (Bollen, 1989), "configural" (Horn $\&$ McArdle, 1992), or "weak" (Meredith \& Teresi, 2006) and is regarded as a reasonable target in assessment studies. Achieving higher levels of invariance, e.g., constraining the factor loadings, factor and error variances and covariances, and factor means to be the same across samples, has been described as "metric" (Horn \& McArdle, 1992) or "strong" (Meredith \& Teresi, 2006), and while rare, is regarded as a more optimal goal for applied research involving measurement of latent constructs.

A slightly different approach to assessing invariance was used in the current study (Rensvold \& Cheung, 1998; Cheung \& Rensvold, 1999). Whereas demonstrating the level of invariance is a goal in many studies of factor invariance, in this study, parameters that lacked invariance were viewed as potentially meaningful and worthy of interpretation and explanation. According to this approach, testing of parameters continues through the entire hierarchy, and the theoretical relevance of invariant and non-invariant parameters that emerge are considered.

All confirmatory analyses were carried out using EQS 6.1 (Bentler, 2006). EQS yields several indices of overall model fit in addition to the scaled chi-square test. Several indices were selected because they are sensitive to different aspects of overall fit (Tanaka, 1993; Hu $\&$ Bentler, 1999). We report the comparative fit index (CFI, Bentler, 1990), the non-normed goodness of fit index (NNFI, Bentler \& Bonett, 1980), and the RMSEA (Browne \& Cudeck, 1993; Steiger, 1990). Generally, CFI and NNFI greater than .90 and RMSEA values less than .06 are indicative of good model fit to the data.

Since models tested in an invariance hierarchy are nested, in addition to these indices of overall model fit, we report additional indices of comparative fit in confirmatory analyses. When comparing the fit of one level of invariance to another we report the $\Delta \chi^{2}, \Delta \mathrm{CFI}$, and $\Delta$ RMSEA between models. The $\Delta \chi^{2}$ between two nested models is also distributed as $\chi^{2}$ with degrees of freedom equal to the the difference in degrees of freedom between models. A significant, negative $\Delta \chi^{2}$ at the $p<.05$ level indicates the hypothesis of invariance should be rejected. Similarly, $\Delta$ CFI and $\triangle$ RMSEA $\geq-.01$ and $\geq .015$, respectively, indicate that the hypothesis of invariance should be rejected (Chen, 2007; Cheng \& Rensvold, 2002). 
Missing Data-Three participants in the recently-widowed sample were missing seven or more TRIG-Present items at 2-months postloss and were removed, bringing the sample size to 209 participants for analyses involving TRIG-Present data at this time point. Nine additional participants in the recently-widowed sample and six participants in the community-dwelling sample were missing at least one item (but no more than six) on the TRIG-Present at the initial assessment. Likewise, eight participants in the recently-widowed sample were missing at least one TRIG-Present item (but no more than six) at 12-months postloss. These missing data did not appear to follow any particular pattern in either sample, at either time of measurement. Assuming data was missing completely at random, we used mean imputation to handle missing data.

\section{Results}

\section{Exploratory Factor Analysis}

TRIG-Present scores appeared to be non-normally distributed in the community-dwelling sample. Normalized Mardia's (1970) kurtosis coefficient equaled 6.21, and values greater than 5 generally indicate deviation from multivariate normality (Bentler, 2006). Exploratory analyses using maximum likelihood (ML) estimation and robust weighted least squares estimation (RWLS; Flora and Curran, 2004), an estimation method that is useful when data violates the multivariate normality, yielded virtually identical results. Thus, we only report analyses using the more traditional ML estimation here.

We extracted one, two, three and four factors for the TRIG-Present using the responses from the community-dwelling sample (eigenvalues were $6.12,1.24,1.04$, and 0.82 respectively). The four factor model did not converge on a solution, and the unifactorial model fit the data poorly, $\chi^{2}(65)=228.33, p<.001$, RMSEA $=.13(90 \% \mathrm{CI}=.11-.15)$.

The 2-factor model did not fit the data well, $\chi^{2}(53)=120.96, p<.001$, RMSEA $=.09(90 \%$ $\mathrm{CI}=.07-.11)$. The 2 -factor solution did significantly improve model fit over the unifactorial model, but interpretability issues arose with the 2-factor model. The two factors included strong loadings (.6 or greater) for six of the 13 items from the TRIG-Present, three items denoting an emotional response to the loss (items 1, 7, and 13), and three items denoting difficulty in accepting the loss (items 3,10 , and 12). The remaining seven items did not load as strongly on either factor and conveyed either a more cognitive aspect of bereavement (e.g., item 6, I am preoccupied with thoughts (often think) about the person who died), or a combination of the cognitive and emotional components of bereavement (e.g., item 2, I still get upset when I think about the person who died).

The 3-factor model fit the data reasonably well, $\chi^{2}(42)=60.23, p<.034$, RMSEA $=.05$, $(90 \% \mathrm{CI}=.01-.08)$, and significantly improved model fit from the 2 -factor model. The factor pattern matrix for the rotated 3-factor solution is located in Table 1 and shows that items generally clustered together to form three distinct factors that may be best described as Emotional Response to the loss, Non-Acceptance of the loss, and Thoughts about the loss. It should be noted that item 4 , Sometimes I very much miss the person who died, and item 8 , No one will ever take the place in my life of the person who died, were relatively weak fitting items with little shared variance. Because the goal of this paper was not to alter but 
rather better understand the TRIG-Present, these two items remained as manifest variables for the factor upon which they loaded strongest, in both cases the Thoughts factor. There was a strong association between the Emotional Response and Nonacceptance factors ( $r=$. 62), the Emotional Response and Thoughts factors $(r=.64)$, and the Nonacceptance and Thoughts factors $(r=.53)$. The 3-factor model was not only empirically superior to the 2 factor model, but the 3-factor model improved the overall interpretability of the structure of TRIG-Present items, assessing three distinct domains of grief. The fit of this 3-factor solution was examined in a sample of recently bereaved older adults.

\section{Confirmatory Factor Analyses across Samples}

The 3-factor solution that emerged from the exploratory factor analysis was then fitted to TRIG-Present data in the recently-widowed sample at 2-months following the loss of a spouse. Factor loadings for one item from each of three identified factors were set to unit value in order to permit factor identification.

Normalized estimates of Mardia's (1970) kurtosis coefficient were 5.67 and 5.45 in the recently-widowed sample at 2 and 12-months, respectively, which indicated some deviation from multivariate normality. Since EQS can utilize ML estimation, which assumes multivariate normality, and also a robust ML estimation procedure, which yields test statistics less biased by deviations from multivariate normality (Satorra \& Bentler, 1988), both ML and robust ML estimation were used in all confirmatory analyses. Results from analyses using ML estimation and robust ML estimation produced virtually identical results. Hence, only results from the more traditional ML estimation method are reported here.

The 3-factor solution fit the data reasonably well in the recently-widowed sample at 2months postloss, $\chi^{2}(62)=129.34, p<.01, \mathrm{NNFI}=.92, \mathrm{CFI}=.94$, and RMSEA $=.072$ $(90 \% \mathrm{CI}=.05-.09)$. All factor loadings and factor variances were significantly different from zero $(p$ 's <.01). Inspection of the modification indices suggested that two correlated errors should be added: between item 13, At times I still feel the need to cry..., and item 1, I still cry when I think of ... (both of which inquire in slightly different ways about crying), as well as between item 8, No one will ever take the place of..., and item 4, Sometimes I very much miss...(both of which inquire about separation distress). These correlated errors are likely due to significant overlap in wording and/or content beyond that measured by the latent factors at 2-months postloss.

Figure 1 includes standardized estimates obtained from independent baseline confirmatory analyses of the modified 3-factor model (which allowed the errors for two pairs of items to correlate) in the recently-widowed sample at 2-months after the loss and in the communitydwelling sample. This modified model provided a significantly better fit to the TRIGPresent data in the recently-widowed sample at 2-months postloss compared to the initial model without correlated errors, $\Delta \chi^{2}(2)=30.62, \mathrm{p}<.01, \Delta \mathrm{CFI}=.02, \Delta \mathrm{RMSEA}=-.02$; overall fit, $\chi^{2}(60)=98.72, p<.01, \mathrm{NNFI}=.95, \mathrm{CFI}=.96$, and $\mathrm{RMSEA}=.052(90 \% \mathrm{CI}=$. $03-.07)$, and it also provided a very good fit to the data from the community-dwelling sample, $\chi^{2}(60)=74.56, p=.09, \mathrm{NNFI}=.97, \mathrm{CFI}=.98$, and $\mathrm{RMSEA}=.044(90 \% \mathrm{CI}=.00$ - .07). All factor loadings, factor variances and covariances, and estimated error covariances were significantly different from zero $(p$ 's $<.01)$. 
Invariance of the factor pattern (constraining the factor pattern to be equivalent in both recently-widowed and community-dwelling samples) was demonstrated for the modified 3factor model, $\chi^{2}(120)=172.15, p<.01, \mathrm{NNFI}=.96, \mathrm{CFI}=.97$, and RMSEA $=.033(90 \%$ $\mathrm{CI}=.02, .05)$. Despite acceptable overall fit, invariance of factor loadings (constraining factor loadings to be equivalent in both recently-widowed and community-dwelling samples) must be rejected based on comparative fit indices, $\chi^{2}(130)=218.05, p<.01$, NNFI $=.94, \mathrm{CFI}=.95$, and RMSEA $=.056(90 \% \mathrm{CI}=.04, .08), \Delta \chi^{2}(10)=45.90, p<.01, \Delta \mathrm{CFI}=$ -.022 , and $\triangle \mathrm{RMSEA}=.023$. When the equality constraint on the factor loading for item $7, I$ hide my tears when I think about him (her), on the Emotional Response factor was dropped, invariance of other factor loadings across samples was demonstrated, $\chi^{2}(129)=186.22, p<$. $01, \mathrm{NNFI}=.94, \mathrm{CFI}=.95$, and RMSEA $=.041(90 \% \mathrm{CI}=.03, .05), \Delta \chi^{2}(9)=14.90, p \geq 12$, $\Delta \mathrm{CFI}=-.004$, and $\Delta \mathrm{RMSEA}=.008$. Freely estimated in each sample, item 7 loaded less strongly on the Emotional Response factor in the recently-widowed sample at 2-months postloss (.25) than in the community-dwelling sample (.74).

All subsequent across-sample invariance analyses dropped the equality constraint on the factor loading for item 7 . With this equality constraint dropped, invariance of error variances was demonstrated (except for the error variance for item 7 which was not constrained to be equal across samples), $\chi^{2}(138)=200.61, p<.01, \mathrm{NNFI}=.94, \mathrm{CFI}=.95$, and RMSEA $=$. $047(90 \% \mathrm{CI}=.04-.06), \Delta \chi^{2}(9)=14.39, p \geq 11, \Delta \mathrm{CFI}=-.003$, and $\Delta \mathrm{RMSEA}=.006$, as was invariance of the two error covariances (between items 1 and 13, and items 4 and 8), $\chi^{2}(140)=202.56, p<.01, \mathrm{NNFI}=.94, \mathrm{CFI}=.95$, and RMSEA $=.048(90 \% \mathrm{CI}=.04-.06)$, $\Delta \chi^{2}(2)=1.95, p \geq 37, \Delta \mathrm{CFI}=-.002$, and $\Delta \mathrm{RMSEA}=.001$.

Despite acceptable overall fit of the constrained model, invariance of factor covariances/ factor variances was not demonstrated according to comparative fit indices, $\chi^{2}(146)=$ $224.01, p<.01, \mathrm{NNFI}=.93, \mathrm{CFI}=.93$, and RMSEA $=.063(90 \% \mathrm{CI}=.05-.08), \Delta \chi^{2}(6)=$ $23.40, p \leq .01, \Delta \mathrm{CFI}=-.017$, and $\triangle \mathrm{RMSEA}=.015$. When the equality constraints were dropped on the covariance between Non-Acceptance and Thoughts factors and on the variance of the Non-Acceptance factor, invariance of other factor covariances/factor variances across samples was demonstrated, $\chi^{2}(144)=209.45, p<.01, \mathrm{NNFI}=.94, \mathrm{CFI}=$. 95 , and RMSEA $=.053(90 \% \mathrm{CI}=.04-.06), \Delta \chi^{2}(4)=6.95, p \geq 14, \Delta \mathrm{CFI}=-.003$, and $\triangle \mathrm{RMSEA}=.005$. Freely estimated in each sample, the association between the NonAcceptance and Thoughts factors was significantly weaker in the recently-widowed group at 2-months postloss (.47) than the community-dwelling sample (.72), and the variance of the Non-Acceptance factor was significantly greater in the recently widowed sample at 2months postloss (1.44) than in the community-dwelling sample (.77). Subsequent invariance tests thus dropped equality constraints on the covariance between Non-Acceptance and Thought factors and on the variance of the Non-Acceptance factor.

Finally, using structured means modeling, the invariance of factor means was evaluated across the recently widowed at 2-month postloss and community-dwelling samples. Despite acceptable overall model fit, invariance of factor means was not demonstrated, $\chi^{2}(147)=$ $267.57, p<.01, \mathrm{NNFI}=.92, \mathrm{CFI}=.92$, and RMSEA $=.076(90 \% \mathrm{CI}=.06-.09), \Delta \chi^{2}(3)=$ $58.12, p<.01, \Delta \mathrm{CFI}=-.021$, and $\triangle \mathrm{RMSEA}=.023$. Means for Non-Acceptance, Thoughts, and Emotional Response factors scores were higher for recently widowed spouses at 2- 
months postloss compared to the community-dwelling sample $(3.46,1.85,3.00$ vs. 2.81 , $1.11,1.24$, respectively).

\section{Confirmatory Factor Analysis across Times of Measurement}

Figure 1 also includes standardized estimates from the baseline confirmatory analysis of the modified 3-factor model in the 164 recently-widowed who were sampled for a second time at 12-months postloss. The modified 3-factor solution fit the data well in the recentlywidowed group at 12 -months postloss, $\chi^{2}(60)=117.63, p<.01$, NNFI $=.93, \mathrm{CFI}=.95$, and RMSEA $=.060(90 \% \mathrm{CI}=.05-.07)$. All factor loadings, factor variances and covariances, and estimated error covariances were significantly different from zero in this analysis as well $(p$ 's $<.01)$.

In all confirmatory invariance analyses across times of measurement common-item errors and factors were permitted to covary across time. Invariance of the factor pattern was demonstrated for the modified 3-factor model from 2 and 12-months postloss in the recently-widowed sample, $\chi^{2}(267)=424.66, p<.001, \mathrm{NNFI}=.92, \mathrm{CFI}=.93$, and RMSEA $=.055(90 \% \mathrm{CI}=.05-.07)$. As in across-sample confirmatory analyses, despite acceptable overall fit, invariance of factor loadings across times of measurement must be rejected based on comparative fit indices: $\chi^{2}(277)=444.67, p<.01, \mathrm{NNFI}=.91, \mathrm{CFI}=.92$, and RMSEA $=.068(90 \% \mathrm{CI}=.05-.09), \Delta \chi^{2}(10)=20.01, p<.05, \Delta \mathrm{CFI}=-.014$, and $\Delta \mathrm{RMSEA}=.014$. When the equality constraint on the factor loading for item 7, I hide my tears when I think about him (her), on the Emotional Response factor was dropped, invariance of other factor loadings was demonstrated across time, $\chi^{2}(276)=431.16, p<.01$, NNFI $=.92, \mathrm{CFI}=.93$, and RMSEA $=.056(90 \% \mathrm{CI}=.05-.07), \Delta \chi^{2}(9)=7.50, p>.58, \Delta \mathrm{CFI}=-.003$, and $\triangle$ RMSEA $=.001$. Freely estimated at each time, item 7 loaded less strongly on the Emotional Response factor in the recently-widowed sample at 2-months postloss (.25) than at 12-months postloss (.47).

Subsequent invariance analyses across times of measurement dropped the equality constraint on the factor loading for item 7. With this equality constraint removed, invariance of error variances was demonstrated across times of measurement (except for the error variance for item 7 which was not constrained to be equal across times), $\chi^{2}(285)=437.61, p<.01$, NNFI $=.92, \mathrm{CFI}=.93$, and RMSEA $=.060(90 \% \mathrm{CI}=.05-.07), \Delta \chi^{2}(9)=6.45, p \geq 69, \Delta \mathrm{CFI}=-$. 004 , and $\triangle \mathrm{RMSEA}=.003$, as was invariance of the two error covariances (between items 1 and 13, and between items 4 and 8$), \chi^{2}(287)=438.88, p<.01, \mathrm{NNFI}=.92, \mathrm{CFI}=.93$, and RMSEA $=.060(90 \% \mathrm{CI}=.05-.07), \Delta \chi^{2}(2)=1.27, p \geq 52, \Delta \mathrm{CFI}=-.001$, and $\Delta \mathrm{RMSEA}=$. 001 .

Invariance of factor covariances/factor variances was also demonstrated across times of measurement, $\chi^{2}(293)=445.24, p<.01, \mathrm{NNFI}=.92$, CFI $=.92$, and RMSEA $=.061(90 \%$ $\mathrm{CI}=.05-.08), \Delta \chi^{2}(6)=6.36, p>.38, \Delta \mathrm{CFI}=-.005$, and $\Delta \mathrm{RMSEA}=.010$.

Finally, using structured means modeling, invariance of factor means was evaluated in the recently widowed at 2 and 12 months postloss. Despite acceptable overall model fit, invariance of factor means across times of measurement was not demonstrated, $\chi^{2}(296)=$ $475.87, p<.01, \mathrm{NNFI}=.90, \mathrm{CFI}=.90$, and RMSEA $=.081(90 \% \mathrm{CI}=.06-.11), \Delta \chi^{2}(3)=$ 
$30.53, p<.01, \Delta \mathrm{CFI}=-.017$, and $\triangle \mathrm{RMSEA}=.020$. Means for Non-Acceptance, Thoughts and Emotional Response factor scores were higher for recently widowed spouses at 2months postloss than at 12 months postloss $(3.46,1.85,3.00$, vs. $3.08,1.36,1.96$, respectively).

\section{Internal Consistency and Test-Retest Reliability}

In both samples, and at both time points in the recently-widowed sample, Non-Acceptance, Emotional Response, and Thoughts factor scores demonstrated a high degree of internal consistency (median $\alpha=.81$, $\alpha$ range .75 to .87 ). In the recently-widowed sample, test-retest correlations from 2 to 12-months postloss for the Non-Acceptance, Thoughts, and Emotional Response factor scores (controlling for synchronous and cross-lagged correlations between factors) were $.70, .80$, and .84 , respectively.

\section{Convergent Validity}

In order to examine the convergent validity of the three TRIG-Present factor scores, these factors were simultaneously regressed on 14 predictors in separate analyses in the recentlywidowed and community-dwelling samples. The effect of each predictor on TRIG-Present factor scores in these regressions, as in typical multiple regression analyses, controls for the effects of the other 13 predictors in the equation.

In both of these analyses, 14 correlations among predictors were freely estimated. Each of these 14 freely estimated correlations were consistent with established theory and findings from past studies. To provide a few examples, associations between neuroticism and depression, physical illness, are consistent with a number of studies indicating that this personality trait is a risk factor for a variety of negative physical and mental health outcomes (Lahey, 2009). With regard to gender, past studies would also suggest that in later-life women tend to live longer than men (explaining the association between gender and age; Mathers, Murray, Lopez, Sadana, \& Salomon, 2002) and are more likely to endorse depressive symptomatology (Zunzunegui et al., 2007). Associations among measures of religious involvement in later life are well established (Ainlay \& Smith, 1984; Chatters, Levin, \& Taylor, 1992).

Results of regression analyses predicting the TRIG-Present factors are presented in Table 2. Measures of fit for the 3-factor TRIG-Present model with correlated predictors in each sample are as follows: In the recently-widowed sample, $\chi^{2}(364)=497.43, \mathrm{p}<.001$, NNFI $=.92, \mathrm{CFI}=.92$, and RMSEA $=.057(90 \% \mathrm{CI}=.03-.08)$; in the community-dwelling sample, $\chi^{2}(364)=489.98, \mathrm{p}<.001, \mathrm{NNFI}=.92, \mathrm{CFI}=.92$, and RMSEA $=.054(90 \% \mathrm{CI}=$. $04-.07)$.

Overall these analyses revealed that older participants had significantly higher levels of normal grief symptoms across all factors in the widowed sample and had higher levels of Non-Acceptance in the community-dwelling sample. In both samples, women tended to have higher scores on the Thoughts and Emotional Response factors. Furthermore, BDI scores and extent of grieving were positively related to each of the three TRIG-Present factors in both samples. It is notable, however, that scores on Wyler's Seriousness of Illness 
Scale were not found to be significantly associated with any of the TRIG-Present factors in either sample. In both the recently-widowed sample and community-dwelling sample, nonorganizational religiosity was associated with lower scores on the Emotional Response factor, and subjective religiosity was associated with lower scores on the Non-Acceptance factor. Notably, openness to experience was also associated with fewer Thoughts about a loss in both samples.

\section{Discussion}

Using two independent samples of bereaved older adults, this study found support for a 3factor model of TRIG-Present scores that assesses bereaved individuals' Emotional Response, Non-Acceptance, and Thoughts regarding a loss. This finding corresponds with theories of grief that view normal grieving as having multiple components, such as Burnett and colleagues' (1997) three "core bereavement phenomena." Notably, other generalpurpose grief measures have also conceptualized grief as a multidimensional construct, most often on theoretical grounds, as with the Core Bereavement Items (Burnett et al., 1997) and Grief Experience Inventory (Sanders, Mauger, \& Strong, 1985), but only occasionally on empirical grounds, as with the Hogan Grief Reaction Checklist (Hogan, Greenfield, \& Schmidt, 2001). It should be noted, however, that the fit of our 3-factor model was improved when the error terms for two pairs of items (i.e., two items worded similarly assessing the need to cry, and two items assessing separation from the deceased) were allowed to correlate, indicating that some TRIG Present score associations are not fully captured by the three factor model.

The TRIG-Present scores associated with the Emotional Response, Non-Acceptance, and Thoughts factors were also found to have high internal consistency and high test-retest reliability in both samples, and the 3-factor model generally demonstrated substantial factorial invariance across community-dwelling and recently-widowed samples as well as longitudinally from 2 to 12 -months postloss in the recently-widowed sample. From a measurement perspective, this across sample and longitudinal invariance, and internal consistency of scores associated with each of the three factors, provides justification for using Emotional Response, Non-Acceptance, and Thoughts regarding the loss as reliable subscales in both the early stages of loss as well as in later stages (i.e., at least up to 1-year postloss).

This finding also has important theoretical implications for the study of normal grieving. Specifically, although several studies suggest that the intensity of core grief symptoms may wax and wane over time, perhaps according to predictable stages (Maciejewski et al., 2007) or for other reasons (e.g., anniversary reactions; Holland \& Neimeyer, in press; Jacobs, Schaefer, Ostfeld, Kasl, \& Berkman, 1987), the present investigation indicates that the form and structure of these grief phenomena remains relatively intact across the first year of spousal bereavement (i.e., symptoms at 2-months postloss generally have the same meaning at 12-months postloss).

Even though the overall trend in these data pointed to invariance for the 3 -factor model across samples and over time, three aspects of the model did appear to change to some 
degree across samples and across time within the recently-widowed sample. First, one TRIG-Present item (i.e., I hide my tears...) loaded more substantially on the Emotional Response factor in the recently-widowed sample at 12-months postloss and in the community-dwelling sample (most of whom had experienced a loss more than one year ago), compared to the recently-widowed sample at 2-months postloss. This finding could indicate that hiding tears is less of an indicator of one's emotional response early on in the grieving process. Indeed, it seems likely that hiding one's tears in the early stages of spousal loss, when outward emotional expression is often viewed as normative by supportive others (Rubin \& Schechter, 1997), might speak more to a bereaved individual's personality (e.g., shyness, stoicism), his or her preferred style of coping (e.g., problem-solving over emotionfocused coping), and/or the particular norms of their social support network (e.g., perhaps to "stay strong" in the face of adversity). Given the ambiguity about its meaning, this particular item should be interpreted cautiously for newly bereaved respondents.

Second, the association between the Non-Acceptance and Thoughts factors was also diminished in the recently-widowed sample compared to the community-dwelling sample. This difference in the magnitude of the association between factors in the two samples suggests that these processes may in fact operate somewhat independently. For example, given the intimacy of a marital relationship (in terms of both emotional and physical proximity), widows and widowers may often be reminded of and think about their lost spouse (Rosenblatt, 1983). These thoughts, however, may be more benign and might not translate into a lack of acceptance in the same way they would for losses of less intimate relationships that occurred in the distant past, as was the case for many participants in the community-dwelling sample.

It is also not entirely surprising that the variability of the Non-Acceptance factor was larger in the community-dwelling sample compared to the recently widowed sample, as these losses occurred under a diversity of circumstances-some of which were likely easier to accept than others (e.g., unexpected vs. expected losses, close friendships vs. less intimate relationships).

Third, the mean scores for each of the three factors, Emotional Response, Non-Acceptance, and Thoughts were lower in the community-dwelling than in the recently-widowed sample at 2 months postloss, and lower in the recently-widowed sample at 12 months postloss than at 2 months postloss. This is to be expected as grief-related Thoughts, Emotional Responses, and Non-Acceptance tend to be more intense for recent losses (i.e., occurring 2- months ago) and losses of intimate relationships (i.e., a spouse). Since the structure of the Emotional Response factor changes, however, across samples and across times of measurement within the recently-widowed, i.e., the factor loading for item 7, I hide my tears when I think about him (her), is not invariant, interpretation of mean differences in Emotional Response should be made with caution.

Beyond simply proposing a 3-factor model for the TRIG-Present and testing its validity, this study has also provided preliminary evidence supporting the concurrent validity and practical applicability of this new model. From a validity perspective, the fact that scores for all three TRIG-Present factors were positively correlated with depressive symptoms 
indicates that each of these factors, to some extent, measures older adults' levels of psychological distress following a loss. It is noteworthy, however, that none of the TRIGPresent factors were associated with physical health in either sample, supporting the notion that this measure taps into less pathological (and more normal) grief processes, compared to a measure like the ICG, which has been shown to predict health outcomes, such as cancer, heart problems, and high blood pressure (Prigerson et al., 1997).

Our findings also suggest that the 3-factor model of the TRIG-Present might help clarify key differences in the expression of grief among older adults with varying demographic characteristics, personality traits, and levels of religiosity. For example, results in both samples indicated that bereaved women might be more likely than bereaved men to endorse items relating to their Emotional Response and Thoughts about loss, which is consistent with past research suggesting that bereaved women engage in more emotion-focused and ruminative coping strategies (see Stroebe et al., 2001, for a review). No gender differences, however, were detected with regard to their levels of Non-Acceptance of a loss, perhaps indicating that gender differences only apply to certain aspects of the grieving process. Indeed, it could be that the degree of Non-Acceptance of a loss might be best viewed as a product or outcome (i.e., one's sense of resolution) of grappling with the reality of the death and is perhaps less influenced by stylistic differences in coping.

With regard to personality traits, we also found important differences. For instance, in both samples, having less openness to experience was associated with more Thoughts about loss but was not strongly related to the Non-Acceptance or Emotional Response factors. This finding could suggest older adults who tend to approach life in a more rule-guided or "down-to-earth" way might experience the death of a loved one as a greater cognitive challenge (as it could pose a greater challenge to their assumptive worldviews; JanoffBulman, 1992), yet still exhibit comparable levels of emotion regulation and acceptance of the ultimate reality of the loss.

Finally, this study also suggests that older adults' subjective religiosity and involvement in informal religious practices might have an impact on specific aspects of the grieving process. With regard to subjective religiosity, we found that believing in the importance of religious involvement was associated with less Non-Acceptance of a loss, which fits with past findings suggesting that religiosity and spirituality might buffer the effects of loss, perhaps by helping bereaved individuals make sense of their losses (Wortman \& Park, 2008). Additionally, engaging in informal religious practices (e.g., meditation or prayer) was associated with less Emotional Response to loss but was not necessarily related to NonAcceptance or Thoughts about a loss. In this case, it could be that certain religiously oriented behavioral practices, like meditation, help individuals regulate their emotions and promote a sense of calmness, perhaps in ways similar to relaxation training. Such an explanation would suggest that some behavioral practices impact specific aspects of grieving and would also support the notion that clinicians and researchers should consider the target of a behaviorally-oriented bereavement intervention (e.g., soothing difficult emotions, challenging thoughts, promoting acceptance) when assessing its effectiveness. 


\section{Future Directions and Limitations}

Notwithstanding these encouraging findings, future work should continue to examine the practical utility of conceptualizing the TRIG-Present in terms of these three factors. Of particular interest are the implications of this model for the assessment of bereavement interventions. We believe that this conceptualization could also promote insights into how bereaved individuals of diverse backgrounds differ in their responses to loss. Although this study was able to address some of these issues (e.g., exploring possible gender differences), limitations of our sample prevented us from addressing factors such as race/ethnicity, as most participants were Caucasian. Thus, future studies that attempt to replicate these findings with ethnically/racially diverse groups could help clarify the extent to which our model generalizes to other samples.

It is also noteworthy that the present sample was made up exclusively of late middle-aged and older adults, and it is possible that replication with younger adults could yield different results. Notably, even with a fairly restricted age range, we observed some interesting trends related to age in our sample. Compared to younger participants, older individuals had higher scores on the Thoughts, Non-Acceptance, and Emotional Response factors in the recentlywidowed sample and had higher scores on the Non-Acceptance factor in the communitydwelling sample. Though the bereavement literature has been mixed regarding the association between age and grief (e.g., Ball, 1977; Sanders, 1981), our findings fit with those of another investigation that found that after about age 60, older participants tend to have higher scores on the TRIG-Present (Ringdal, Jordhøy, Ringdal, \& Kaasa, 2001). The authors of this study interpreted their findings as perhaps resulting from greater isolation and less social support among older participants. Another explanation has been offered by Rosenblatt (1983) in his study of $19^{\text {th }}$ century, recently-widowed diarists. In this qualitative investigation, older, longer-married survivors described more loss-related thoughts and experiences in their diaries, particularly if they had co-resided with their lost spouse. Rosenblatt attributed this finding to the fact that these widows/widowers likely encountered stronger and more prominent "reminders" of loss. Despite the intuitive appeal of these explanations, future work that examines normal grief among varying age groups could clarify how and why these phenomena might differ with age.

Finally, it should be noted that the longitudinal invariance of this 3-factor model was only tested from 2 to 12-months postloss, and future studies would do well to examine this model at later time points (e.g., at 2 or 4-years postloss). The fact that our 3-factor model generalized to participants in a community-dwelling sample (many of whom had lost loved ones several years prior), however, certainly bodes well for the stability of this model beyond 12-months postloss.

Notwithstanding these limitations and possibilities for future work, we believe the present findings provide clinicians and researcher with an improved model for the TRIG-Present, one of the most established and widely used grief measures, which will likely enhance assessment and understanding of bereavement phenomena. 


\section{Acknowledgments}

This research was supported in part by grants MH37196 from the National Institute of Mental Health and AG01759 from the National Institute on Aging to Larry W. Thompson, grant AG11438 from the National Institute on Aging to Andrew Futterman, and by training grant 5 T32 AG 00030 from the National Institute on Aging to Martha Storandt. The authors wish to thank Martha Storandt and Carol Woods for their generous help and thoughtful critiques on earlier drafts of this manuscript.

\section{References}

Ainlay S, Smith R. Aging and religious participation. Journal of Gerontology. 1984; 39:357-363. [PubMed: 6715815]

Ball JF. Widow's grief: The impact of age and mode of death. Omega. 1977; 7:307-333.

Beck AT, Ward CH, Mendelson M, Mock J, Erbaugh J. An inventory for measuring depression. Archives of General Psychiatry. 1961; 4:561-571. [PubMed: 13688369]

Bentler P, Bonett DG. Significance tests and goodness of fit in the analysis of covariance structures. Psychological Bulletin. 1980; 88:588-606.

Bentler P. Comparative fit indexes in structural models. Psychological Bulletin. 1990; 107:238-246. [PubMed: 2320703]

Bentler, P. EQS 6 Structural Equations Program Manual. Multivariate Software; Encino, CA: 2006.

Boelen PA, van den Bout J. Complicated grief and uncomplicated grief are distinguishable constructs. Psychiatry Research. 2008; 157:311-314. [PubMed: 17916387]

Boelen PA, van den Bout J, Keijser J, Hoijtink H. Reliability and validity of the Dutch version of the Inventory of Traumatic Grief (ITG). Death Studies. 2003; 27(3):227-247. [PubMed: 12703504]

Bollen, KA. Structural equations with latent variables. Wiley; New York: 1989.

Bonanno GA, Wortman CB, Lehman DR, Tweed RG, Haring M, Sonnega J, et al. Resilience to loss and chronic grief: A prospective study from preloss to 18-months postloss. Journal of Personality and Social Psychology. 2002; 83(5):1150-1164. [PubMed: 12416919]

Browne, ME.; Cudeck, R. Alternate ways of assessing model fit. In: Bollen, KA.; Long, JS., editors. Testing structural equations models. Sage; Newbury Park, CA.: 1993. p. 1136-162.

Burnett P, Middleton W, Raphael B, Martinek N. Measuring core bereavement phenomena. Psychological Medicine. 1997; 27:49-57. [PubMed: 9122308]

Cattell, RB.; Eber, HW.; Tatsuoka, MM. Handbook for the Sixteen Personality Factors Questionnaire (16PF). Institute for Personality and Ability Testing; Champaign, Illinois: 1970.

Chatters L, Levin JS, Taylor RJ. Antecedents and dimensions of religious involvement among older black adults. Journal of Gerontology. 1992; 47:S269-S278. [PubMed: 1430864]

Chen FF. Sensitivity of goodness of fit indexes to lack of measurement invariance. Structural Equations Modeling. 2007; 14:464-504.

Chen FF. What happens if we compare chopsticks with forks? The impact of making in appropriate comparisons in cross-cultural research. Journal of Personality and Social Psychology. 2008; 95:1005-1018. [PubMed: 18954190]

Cheung GW, Rensvold RB. Testing factorial invariance across groups; a reconceptualization and a proposed new method. Journal of Management. 1999; 25:1-27.

Cheung GW, Rensvold RB. Evaluating goodness-of-fit indexes for testing measurement invariance. Structural Equation Modeling. 2002; 9:233-255.

Costa PT, McCrae R. Age differences in personality structure: A cluster analytic approach. Journal of Gerontology. 1976; 31:564-570. [PubMed: 950450]

Currier JM, Neimeyer RA, Berman JS. The effectiveness of psychotherapeutic interventions for bereaved persons: A comprehensive quantitative review. Psychological Bulletin. 2008; 134(5): 648-661. [PubMed: 18729566]

Davis, CG. Redefining goals and redefining self: A closer look at posttraumatic growth following loss In: Stroebe, MS.; Hansson, RO.; Schut, H.; Stroebe, W.; Van den Blink, E., editors. Handbook of bereavement research and practice: Advances in theory and intervention. American Psychological Association; Washington, DC, US: 2008. p. 309-325. 
Dillen L, Fontaine JRJ, Verhofstadt-Denéve L. Are normal and complicated grief different constructs? A confirmatory analytic test. Clinical Psychology and Psychotherapy. 2008; 15:386-395. [PubMed: 19115457]

Donnelly EF, Field NP, Horowitz MJ. Expectancy of spousal death and adjustment to conjugal bereavement. Omega. 2000; 42:195-208.

Faschingbauer, TR. Texas revised inventory of grief manual. Honeycomb Publishing Co.; Houston, Texas: 1981.

Faschingbauer TR, DeVaul RA, Zisook S. Development of the Texas Inventory of Grief. American Journal of Psychiatry. 1977; 134:696-698. [PubMed: 869041]

Flora DB, Curran PJ. An empirical evaluation of alternative methods of estimation for confirmatory factor analysis with ordinal data. Psychological Methods. 2004; 9(4):466-491. [PubMed: 15598100]

Gallagher DE, Breckenridge J, Steinmetz J, Thompson LW. The Beck Depression Inventory and the Research Diagnostic Criteria. Journal of Consulting and Clinical Psychology. 1983; 51:945-946. [PubMed: 6655109]

Gallagher DE, Breckenridge JN, Thompson LW, Peterson JA. Effects of bereavement on indicators of mental health in elderly widows and widowers. Journal of Gerontology. 1983; 38:565-571. [PubMed: 6886312]

Hays JC, Gold DT, Peiper CF. Sibling bereavement in late life. Omega: Journal of Death and Dying. 1997; 35(1):25-42.

Hogan NS, Greenfield DB, Schmidt LA. Development and validation of the Hogan Grief Reaction Checklist. Death Studies. 2001; 25:1-31. [PubMed: 11503760]

Holland JM, Currier JM, Gallagher-Thompson D. Outcomes from the Resources for Enhancing Alzheimer's Caregiver Health (REACH) program for bereaved caregivers. Psychology \& Aging. 2009; 24:190-202. [PubMed: 19290751]

Holland JM, Neimeyer RA. An examination of stage theory of grief among individuals bereaved by natural and violent causes: A meaning-oriented contribution. Omega. (in press).

Horn JL, McCardle JJ. A practical and theoretical guide to measurement invariance in aging research. Experimental Aging Research. 1992; 18(3):117-144. [PubMed: 1459160]

$\mathrm{Hu}$ L, Bentler P. Cutoff criteria for fit indexes in covariance structure analysis: Conventional criteria versus new alternatives. Structural Equation Modeling. 1999; 6(1):1-55.

Jacobs, S. Pathologic grief: Maladaptations to loss. American Psychiatric Press; Washington, DC: 1993.

Jacobs SC, Schaefer C, Ostfeld A, Kasl SV, Berkman L. The first anniversary of bereavement. Israel Journal of Psychiatry and Related Sciences. 1987; 24:77-85. [PubMed: 3443542]

Janoff-Bulman, R. Shattered assumptions: Toward a new psychology of trauma. Free Press; New York: 1992.

Kitson GC. Adjustment to violent and natural deaths in later and earlier life for black and white widows. The Journals of Gerontology Series B: Psychological and Social Sciences. 2000; 55:S341-S351.

Kübler-Ross, E.; Kessler, D. On grief and grieving: Finding the meaning of grief through the five stages of loss. Scribner; New York, NY: 2005.

Lahey BB. Public health significance of neuroticism. American Psychologist. 2009; 64:241-256. [PubMed: 19449983]

Lund DA, Dimond MF, Caserta MS, Johnson RJ, Poulton JL, Connelly JR. Identifying elderly with coping difficulties after two years of bereavement. Omega. 1986; 16:213-224.

Maciejewski PK, Zhang B, Block SD, Prigerson HG. An empirical examination of the stage theory of grief. JAMA: Journal of the American Medical Association. 2007; 297(7):716-723.

Mardia KV. Measures of multivariate skewness and kurtosis with applications. Biometrika. 1970; 57:519-530.

Mathers CD, Murray C, Lopez A, Sadana R, Salomon J. Global patterns of healthy life expectancy for older women. Journal of Women \& Aging. 2002; 14:99-117. [PubMed: 12537282] 
Meredith W, Teresi JA. An essay on measurement and factorial invariance. Medical Care. 2006; 44(11):S69-S77. [PubMed: 17060838]

Meuser TM, Marwit SJ. An integrative model of personality, coping, and appraisal for the prediction of grief involvement in adults. Omega. 2000; 40:375-393.

Muthen, LK.; Muthen, BO. Mplus: Statistical analysis with latent variables. Fourth Edition. Muthen \& Muthen; Los Angeles, CA: 2006.

Neimeyer, RA.; Hogan, NS.; Laurie, A. The measurement of grief: Psychometric considerations in the assessment of reactions to bereavement. In: Stroebe, MS.; Hansson, RO.; Schut, H.; Stroebe, W.; Van den Blink, E., editors. Handbook of bereavement research and practice: Advances in theory and intervention. American Psychological Association; Washington, DC, US: 2008. p. 133-161.

Olin JT, Schneider LS, Eaton EM, Zemansky MF, Pollock VE. The Geriatric Depression Scale and the Beck Depression Inventory as screening instruments in an older outpatient population. Psychological Assessment. 1992; 4:190-192.

Paulhan I, Bourgeois M. Le questionnaire de deuil TRIG (Texas Revised Inventory of Grief). traduction française et validation. / The Texas Revised Inventory of Grief (TRIG): French translation and validation. L'Encéphale. 1995; 21(4):257-262.

Prigerson HG, Bierhals AJ, Kasl SV, Reynolds CF, Shear MK, Day N, et al. Traumatic grief as a risk factor for mental and physical morbidity. American Journal of Psychiatry. 1997; 154:616-623. [PubMed: 9137115]

Prigerson HG, Maciejewski PK, Reynolds CF, Bierhals AJ, Newsom JT, Fasiczka A, et al. Inventory of Complicated Grief: A scale to measure maladaptive symptoms of loss. Psychiatry Research. 1995; 59(1-2):65-79. [PubMed: 8771222]

Rensvold RB, Cheung GW. Testing measurement models for factorial invariance: A systematic approach. Educational and Psychological Measurement. 1998; 58:1017-1034.

Rosenblatt, P. Bitter, bitter tears: Nineteenth-century diarists and twentieth-century grief theories. University of Minnesota Press; Minneapolis, MN: 1983.

Ringdal GI, Jordhøy MS, Ringdal K, Kaasa S. Factors affecting grief reactions in close family members to individuals who have died of cancer. Journal of Pain and Symptom Management. 2001; 22:1016-1026. [PubMed: 11738164]

Rosenzweig A, Prigerson H, Miller MD, Reynolds CF. Bereavement and late-life depression: Grief and its complications in the elderly. Annual Review of Medicine. 1997; 48:421-428.

Rubin SS, Schechter N. Exploring the social construction of bereavement: Perceptions of adjustment and recovery in bereaved men. American Journal of Orthopsychiatry. 1997; 6:279-289. [PubMed: 9142361]

Sanders CM. Comparison of younger and older spouses in bereavement outcome. Omega. 1981; 11:217-232.

Sanders, CM.; Mauger, PA.; Strong, PN. A manual for the Grief Experience Inventory. Center for the Study of Separation and Loss; Blowing Rock, NC: 1985.

Satorra A, Bentler P. Scaling corrections for chi square statistics in covariance structure analysis. Proceedings of the American Statistical Association. 1988:308-313.

Steiger JS. Structural model evaluation and modification: an interval estimation approach. Multivariate Behavioral Research. 1990; 25(2):173-180.

Strada EA. Grief, demoralization, and depression: Diagnostic challenges and treatment modalities. Primary Psychiatry. 2009; 16:49-55.

Stroebe, W.; Stroebe, MS. Bereavement and health: The psychological and physical consequences of partner loss. Cambridge University Press; New York: 1987.

Stroebe M, Stroebe W, Schut H. Gender differences in adjustment to bereavement: An empirical and theoretical review. Review of General Psychology. 2001; 5:62-83.

Tanaka, JS. Multifaceted conceptions of fit in structural equations models. In: Bollen, KA.; Long, JS., editors. Testing structural equations models. Sage; Newbury Park, CA.: 1993. p. 10-39.

Thompson LW, Gallagher-Thompson D, Futterman A, Gilewski MJ, Peterson J. The effects of late-life spousal bereavement over a 30-month interval. Psychology and Aging. 1991; 6:434-41. [PubMed: 1930760] 
Wilson S. The validation of the Texas Revised Inventory of Grief on an older Latino sample. Journal of Social Work in End-of-Life \& Palliative Care. 2006; 2(4):33-60. [PubMed: 17387094]

Wortmann JH, Park CL. Religion and spirituality in adjustment following bereavement: An integrative review. Death Studies. 2008; 32:703-736. [PubMed: 18958959]

Wyler AR, Masuda M, Holmes TH. Seriousness of illness rating scale. Journal of Psychosomatic Research. 1968; 11:363-374. [PubMed: 5650597]

Zisook S, DeVaul RA, Click MA. Measuring symptoms of grief and bereavement. American Journal of Psychiatry. 1982; 139:1590-1593. [PubMed: 7149059]

Zunzunegui M, Minicuci N, Blumstein T, Noale M, Deeg D, Jylhä M, et al. Gender differences in depressive symptoms among older adults: A cross-national comparison: The CLESA project. Social Psychiatry and Psychiatric Epidemiology. 2007; 42:198-207. [PubMed: 17450402] 


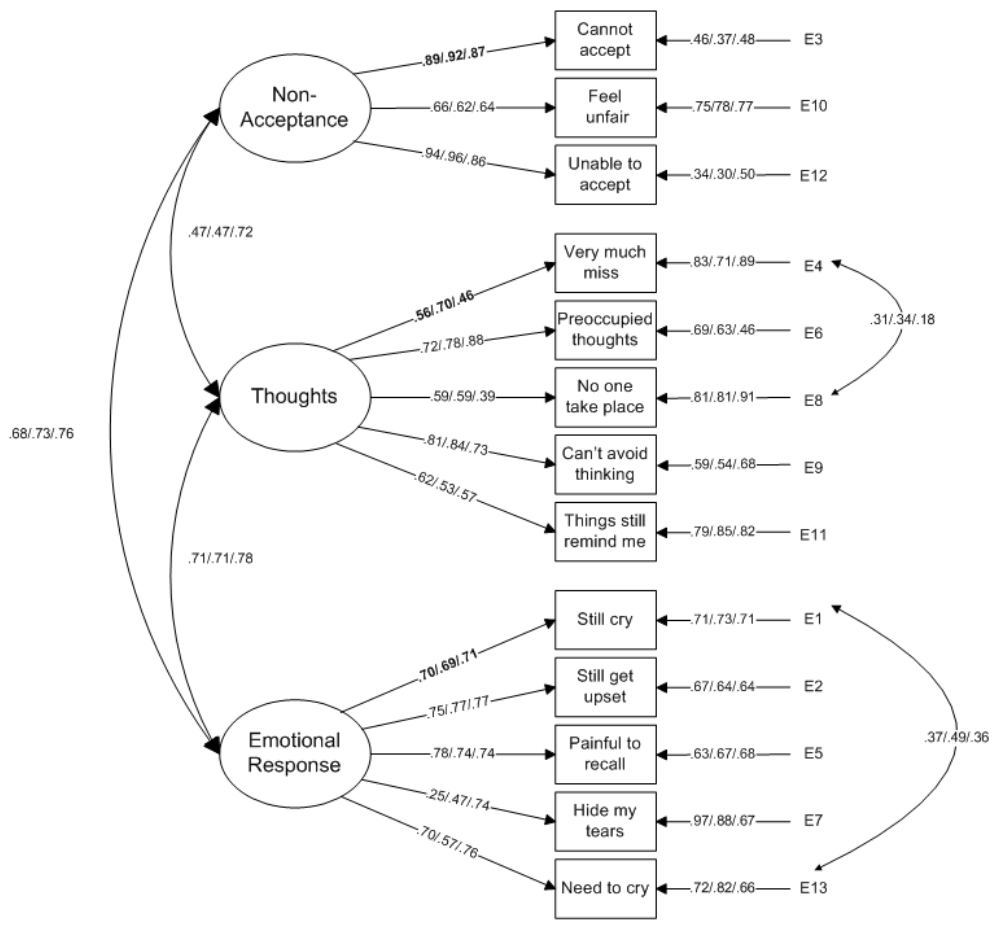

Figure 1.

Results of confirmatory analyses of the 3-factor model of grief in the recently-widowed sample at 2 and 12-months following the loss of a spouse (N's = 209 and 164, respectively) and in the community-dwelling sample $(\mathrm{N}=162)$. The first and second estimates are for the recently-widowed sample at 2 and 12-months postloss, respectively. The third estimate is for the community-dwelling sample. Estimates in bold are set to unit value. 
Table 1

Rotated Exploratory Factor Loadings for a 3-Factor Model of Grief in the Community-Dwelling Sample

\begin{tabular}{|c|c|c|c|c|}
\hline \multirow[b]{2}{*}{ Items } & \multicolumn{4}{|c|}{ Community-Dwelling Sample ( $=162)$} \\
\hline & $\begin{array}{l}\text { Emotional } \\
\text { Response }\end{array}$ & $\begin{array}{l}\text { Non- } \\
\text { Acceptance }\end{array}$ & Thoughts & $\begin{array}{l}\text { Explained } \\
\text { Variance }\end{array}$ \\
\hline $\begin{array}{l}\text { 1. I still cry when I think of the person } \\
\text { who died. }\end{array}$ & .83 & .01 & .00 & .64 \\
\hline $\begin{array}{l}\text { 2. I still get upset when I think about the } \\
\text { person who died. }\end{array}$ & .46 & .43 & .00 & .59 \\
\hline 3. I cannot accept this person's death. & .00 & .88 & .18 & .80 \\
\hline $\begin{array}{l}\text { 4. Sometimes I very much miss the } \\
\text { person who died. }\end{array}$ & .18 & .08 & .27 & .21 \\
\hline $\begin{array}{l}\text { 5. Even now it's painful to recall } \\
\text { memories of the person who died. }\end{array}$ & .44 & .31 & .07 & .52 \\
\hline $\begin{array}{l}\text { 6. I am preoccupied with thoughts } \\
\text { (often think) about the person who died. }\end{array}$ & .07 & .22 & .66 & .72 \\
\hline $\begin{array}{l}\text { 7. I hide my tears when I think about the } \\
\text { person who died. }\end{array}$ & .64 & .11 & .04 & .54 \\
\hline $\begin{array}{l}\text { 8. No one will ever take the place in my } \\
\text { life of the person who died. }\end{array}$ & .27 & .00 & .31 & .22 \\
\hline $\begin{array}{l}\text { 9. I can't avoid thinking about the } \\
\text { person who died. }\end{array}$ & .00 & .01 & .86 & .66 \\
\hline $\begin{array}{l}\text { 10. I feel it's unfair that this person } \\
\text { died. }\end{array}$ & .04 & .67 & .00 & .44 \\
\hline $\begin{array}{l}\text { 11. Things and people around me still } \\
\text { remind me of the person who died. }\end{array}$ & .07 & .10 & .46 & .33 \\
\hline $\begin{array}{l}\text { 12. I am unable to accept the death of } \\
\text { the person who died. }\end{array}$ & .03 & .79 & .07 & .71 \\
\hline $\begin{array}{l}\text { 13. At times I still feel the need to cry } \\
\text { for the person who died. }\end{array}$ & .88 & .00 & .10 & .76 \\
\hline
\end{tabular}

Note. Items are from Texas revised inventory of grief manual, by T.R. Faschingbauer, 1981, Houston, Texas: Honeycomb Publishing Co. Copyright 1981 by T.R. Faschingbauer. Reprinted with permission.

All items scored on Likert scale, 1 "Completely false" to 5 "Completely true". Factor estimation method: Maximum Likelihood; Factor rotation method: Promax. 


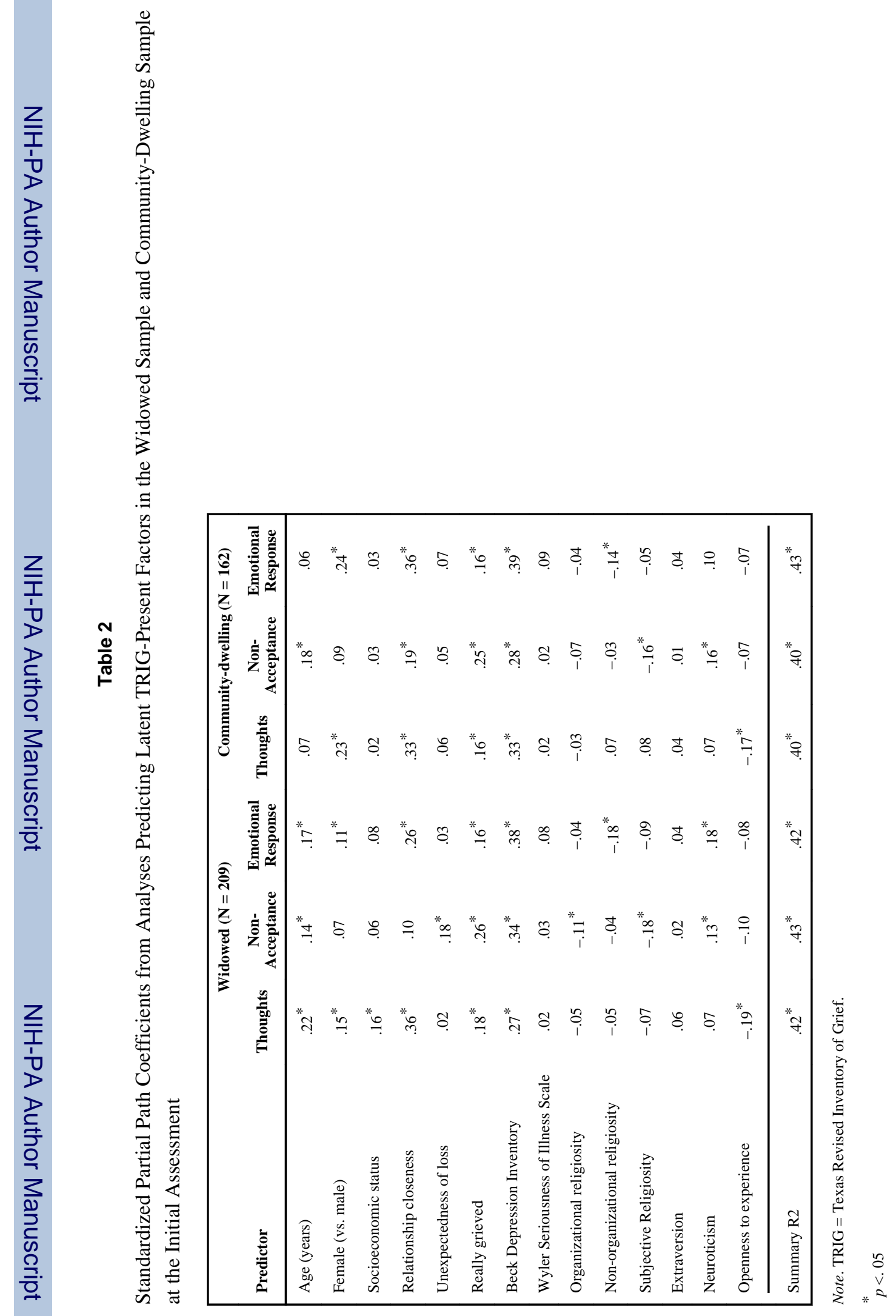

Psychol Assess. Author manuscript; available in PMC 2015 February 21. 